\title{
Finding the Balance: Intoxication and Consent
}

\author{
Amanda Clough ${ }^{1}$ \\ Published online: 5 April 2019 \\ (c) The Author(s) 2019
}

\begin{abstract}
Sexual offences in England and Wales have had a dramatic reimagining in the last 15 years, with the Sexual Offences Act 2003 establishing not only the boundaries of the most heinous of offences such as rape, but also defining one of the most important elements; consent. This article seeks to explore the problems that surround establishing if legally valid consent has been given, with particular regard for cases where voluntary intoxication takes centre stage. The problem that often arises is the question on whether or not an intoxicated victim had the capacity to consent, or establishing if she did consent when memory of the event is hazy, possibly from both parties. Using comparative analysis with other jurisdictions and their take on the offence of rape, the author seeks to discover if the current rules are sufficient to fit within twenty-first century western culture. The victim will be referred to as 'she', although the law here and all situations discussed are equally applicable to male rape.
\end{abstract}

Keywords Consent $\cdot$ Rape $\cdot$ Intoxication

\section{Introduction}

The government have expressed concern as to whether protection is sufficient for individuals who are vulnerable and may generally lack capacity to consent to sexual relations. ${ }^{1}$ Rape law in itself is an intricate set of rules, asking for non-consensual intentional penile penetration without reasonable belief in consent. ${ }^{2}$ This is additionally given a three-tiered explanation and presumption about consent and when it can be legally given. ${ }^{3}$ Add to this a substance which can lower inhibitions and cause

\footnotetext{
1 Dougal (unreported) 2005, Swansea Crown Court.

2 S1 Sexual Offences Act 2003.

3 S74-s76 Sexual Offences Act 2003.

Amanda Clough

A.clough@1jmu.ac.uk

1 Liverpool John Moores University, Liverpool, UK
} 
memory loss, it is no wonder that the courts find difficulty in navigating accusations of rape involving intoxication.

It has been suggested that much benefit would be gained from judicial guidance on the types of situation in which consent cannot be established, ${ }^{4}$ though judicial training is currently requested of judges every three years to remain eligible to deal with such cases. ${ }^{5}$ The Judicial College's Serious Sexual Offences Seminar Programme covers legal, evidential and social issues, as well as sentencing and updating of knowledge. ${ }^{6}$ This includes the impact of stereotyping on decision-making, a vitally important part of the process for cases involving intoxication, where the victim is often blamed for her own demise. It also covers judicial directions on the meaning of capacity and consent, another fundamental component to intoxicated rape cases.

Consent is a tricky concept, as it does not relate directly to desire, but to willingness, and this can vary in degrees. ${ }^{7}$ It can also be expressed verbally whilst non-verbal clues speak louder of an unwillingness to go through with an act. ${ }^{8}$ This in itself is problematic, especially for patriarchal tropes, as Kramer has observed:

Her lack of resistance may sound like a resounding "yes" to a man who subscribes to the traditional model of male aggression and female submission. ${ }^{9}$

What in fact might be happening is that the victim, having weighed up the accused's physical size and strength against her own, decides struggling would not only be futile, but might make her situation even worse. ${ }^{10}$ Such decision-making as to what is in their own best interest at the time may signify that the victim did have the capacity to make such a decision in regards to consent-but not the freedom of choice the law requires. It is much more difficult to enter the realm of whether or not legal capacity to consent is present. In Malone, ${ }^{11}$ the court of appeal spoke of being physical unable to resist, but capacity to consent presumably asks of an assessment of the mind.

\section{The Importance of Intention}

Capacity and intoxication cause limitless problems in the courtroom when a person is accused of rape. The capacity issue often leaves the accused and the victim arguing over either the level of intoxication, or if consent was given at all. The victim may argue that either she was too drunk to have the capacity to consent, or that she cannot remember the exact situation at the time of intercourse taking place, but

\footnotetext{
4 Simpson (2016: 115).

5 Rumney and Fenton (2011: 475).

6 Rumney and Fenton (2011: 475).

7 Malm (1996: 148).

8 Malm (1996: 162).

9 Kramer (1994: 121).

10 Kramer (1994: 144).

11 Malone (1998) 2 CAR 447.
} 
knows she did not want to have sex with the accused. ${ }^{12}$ Discovering the exact level of capacity and intoxicated state are often rather difficult after the fact, and although the prosecution may use experts to calculate how intoxicated a victim was, the metabolic rate and many other factors will often skew such a reading. ${ }^{13}$

The victim's understanding of her situation might also be heavily compromised before capacity to consent is legally lost. If she invites the accused to her abode for a drink, does she apprehend that he may see this as agreement to engage in sexual relations? In the case of Bromwich, ${ }^{14}$ raised eyebrows were said by the accused to have communicated a willingness to engage in sexual activity. What if the victim accepts a car ride from a stranger because she is intoxicated, alone, and knows she needs to get home? Would she understand that this may signify a 'willingness'? It is important to note that such an indeterminate signal of 'willingness' certainly would not equate to consent. In the case of $\mathrm{H}^{15}$ the victim had become separated from her friends, and accepted a car ride from a group of men unknown to her. She claimed that in the back seat, her clothes were pushed into her face and she felt almost unable to breathe, muffling her insistence that he stop (over loud music). The defence argued that because the victim had rejected earlier advances in the care from the accused and others, she had the capacity to do so at the time of the intercourse in question. In this situation, not only was the victim heavily intoxicated and had taken risks she would not have sober, such as getting into a stranger's car, but she also appears to have physically lacked capacity to speak and be heard due to the circumstances.

What of the accused's intentions? Although the victim may have agreed to drink alcohol that evening, how much should the accused's intentions and subsequent behaviour factor into this equation? Wallerstein distinguishes between voluntary intoxication which is and is not assisted by the accused, ${ }^{16}$ though even if the accused is not 'helping to get her drunk', it could be said that he still takes advantage of her intoxicated state. By this, we mean he takes advantage of her uninhibited state with the knowledge that she may not accept his advances if she were sober. Does this give him mens rea? Although this seems to be a moral wrong, ${ }^{17}$ as long as the victim retained the capacity to consent, it is not a legal wrong. Ryan also questions this state of mind and intention of the accused:

Did he think the woman wanted to have sex or did he take advantage of her condition ${ }^{18}$

\footnotetext{
12 Cowan (2008: 901).

13 See Cowan (2008: 908).

14 Bromwich [2012] EWCA Crim 673 [12].

$15 \mathrm{H}$ [2007] EWCA Crim 2056.

16 Wallerstein (2009: 319).

17 Wallerstein (2009: 319).

18 Ryan (2004: 408).
} 
It was established in a study with focus groups given a situation similar to the facts of the case of Bree ${ }^{19}$ that respondents agreed the accused had been foolish and morally wrong in taking advantage of an intoxicated girl, but again not necessarily legally wrong. ${ }^{20}$ Bree is a particularly famous case in this area, having featured a drunk accused and a drunk victim who had spent the evening consuming alcohol together. Her belief the following day was that she had not willingly taken part in sexual intercourse the night before, after the accused had helped her to shower and put her to bed. Not particularly wanting sex and being unable to show reluctance due to intoxication are two very different legal situations. ${ }^{21}$ The courts will begin by presuming the victim had the capacity to consent unless the intoxication was involuntary, but this can be rebutted. ${ }^{22}$ In a similar study with 168 mock jurors and an intoxicated victim who was confused, stumbling and slurring, participants referred to the victim retaining capacity to say no as long as she was conscious, ${ }^{23}$ though one mock juror did point out that her state had resulted in her lacking capacity to make any sort of rational judgment. ${ }^{24}$ If a small group of respondents cannot agree on the point at which capacity is lost, it is not surprising that we are left with an unpredictable legal test. ${ }^{25}$

If the accused buys the victim drinks, or stronger drinks than requested, is this using alcohol as a weapon against sexual reluctance $?^{26}$ One study has shown that $66 \%$ of men had in fact given a woman alcohol at some time so that should be more willing to engage in sexual intercourse. ${ }^{27}$ The important question is, did the accused administer or help in administering alcohol in order to obtain intercourse, or to obtain consent ? $^{28}$ It has been suggested that beginning with a presumption of nonconsent for voluntarily intoxicated victims might be necessary, especially if the victim is vomiting or unable to walk unaided. ${ }^{29}$ As the law stands at the moment, post Bree, it would appear that a victim is capable of consenting legally as long as she is capable of walking, talking or vomiting. ${ }^{30}$ The level of intoxication required in order to negate capacity has been described as unbelievably high. ${ }^{31}$ However, if capacity meant only the technical ability to express a preference, would its inclusion in s74 of the Sexual Offences Act 2003 not be redundant $?^{32}$ Physical inability to express

\footnotetext{
19 Bree [2007] EWCA Crim 256.

${ }^{20}$ Gunby et al. (2013: 94).

21 Zafar (Unreported) 1993.

22 Elliott and De Than (2007: 241).

23 Finch and Munro (2006: 314).

24 Finch and Munro (2006: 315).

25 Finch and Munro (2006: 315).

26 Kramer (1994: 123).

27 Kramer (1994: 123).

28 Finch and Munro (2004: 791).

29 Topping (2016: 91).

${ }^{30}$ Cowan (2008: 918).

31 Firth (2011: 112).

32 Wallerstein (2009: 321).
} 
consent is not required in order for capacity to be negated, but case law seems to suggest otherwise.

The Sexual Offences Act 2003 itself refers only to involuntary intoxication, where it will be presumed that there was no consent if the defendant supplied the victim such substances without her consent or knowledge ${ }^{33}$ Interestingly, this provision covers not only substances administered, but 'caused to be taken'. Is this intended to include a broader range of situations, where stronger drinks are bought or social pressures cause increased consumption ${ }^{34}$ If the victim has consented to consuming alcohol, but is aided or even deceived in consuming more than intended, whether or not this is included in the rebuttable presumption of 'caused to be taken' is open to interpretation. ${ }^{35}$

\section{Involuntary Intoxication and Consent}

We do know that administering substances with the intent that it will enable the victim to be overpowered for purposes of sexual activity is a crime in itself. ${ }^{36}$ What this does not appear to include is if the substance is administered in order to loosen inhibitions and allow the victim to make choices she would not usually make. Less force is needed to get a heavily intoxicated victim to succumb, but as force is not a necessary component of rape at all, criminalising the use of intoxicating substances to dispel resistance is pivotal. However, a substance capable of 'stupefying or overpowering' as section 61 requires does suggest use of force rather than an inability to refuse to consent. ${ }^{37}$ Neither of these words are defined by the statute, and so the exact scope of section 61 remains unclear. ${ }^{38}$

It is also interesting that even in a case of involuntary intoxication; lack of consent is only a presumption that may be rebutted. Presumably, this can protect cases where the victim is given a substance, but not by the accused, hence the use of 'any person' in the section. ${ }^{39}$ It asks that the intoxicating substance be capable of stupefying or overpowering the victim, rather than that it actually does. This means that the actual effect on the victim could be that of releasing a desire to engage in sexual activity, rather than creating one. More concerning is the if the substance is capable of rendering the victim unable to understand their actions. If the victim did consent whilst she was (unbeknown to her) under the influence of an intoxicating substance, can we respect this decision ? $^{40}$

It is difficult to find the right balance between people having sexual desires and happy to act upon them when intoxicated and protecting people from their own

\footnotetext{
33 S75(2)(f).

34 Finch and Munro (2004: 794).

35 Finch and Munro (2004: 796).

36 S61 Sexual Offences Act 2003.

37 Finch and Munro (2004: 801).

38 Elvin (2008: 153).

39 S75(2)(f) Sexual Offences Act 2003.

40 Ryan (2004: 408).
} 
intoxicated state. It is even more difficult when a person is not responsible for their intoxicated state. As Ryan has noted, a person may be responsible for many consequences as a result of self-intoxication including illness, vomiting, and harming others. However, this does not mean she is also responsible for the actions of others towards her. ${ }^{41}$ When she is not responsible for her intoxication, she cannot be said to be responsible of any of these consequences. However, the case of Kingston did prove that drunk intent is still intent, no matter the reason for the intoxicated state, and so the same rules would likely apply. ${ }^{42}$ If you are involuntarily put in a situation where you will make decisions you would not if sober, but you make that decision and have the capacity to do so, it will legally stand. The empathy for the fact that you would not have made that situation nor taken the drink to enable the action is something that would be relevant for sentencing in a case like Kingston, because a child was harmed. ${ }^{43}$ For a case involving an involuntarily intoxicated complainant who retains capacity to consent to sexual intercourse and does so, she is a victim of her own decision, and must live with it.

There is no reason why involuntary intoxication should automatically preclude valid consent unless it has the desired effect of stupefying beyond realms of capacity, however, it does attribute 'moral weight to the defendant's prior fault' ${ }^{44}$ With this in mind, the balance for involuntary intoxication cases appears to already have been achieved by beginning with a presumption of non-consent, which can be rebutted be the accused. Finch and Munro described this concept as one that should be 'welcomed', since meaningful choice might still be made in such circumstances. ${ }^{45}$ However, it is still questionable if meaningful choices are made at all when intoxicated, compared with our sober selves. The Kingston case is surely a warning as to that. Perhaps in such situations, jurors may find it very difficult not to over-attribute blame to a defendant who was aware of the victim's involuntary intoxicated state, regardless of any decisions she might have made. ${ }^{46}$ Since there is the availability of a section 61 charge if the defendant did intoxicate the victim, perhaps a rape conviction may not be the answer. ${ }^{47}$

In Lang, ${ }^{48}$ the trial judge said the critical question was not how a complainant came to take a drink but if she understood the situation and was capable of making up her mind. This certainly seems to put all cases of intoxication, voluntary or involuntary, on the same footing. The only advancement to this since the 2003 change in the law would be the presumption we start with depending on how the complainant ended up drunk.

\footnotetext{
${ }^{41}$ Ryan (2004: 423).

42 Kingston (1994) WLR 519 (1995) 2 AC 355.

43 Kingston (1995) 2 AC 355, 357.

${ }^{44}$ Finch and Munro (2004: 789).

45 Finch and Munro (2004: 794).

46 Finch and Munro (2004: 798).

47 Elvin (2008: 152).

${ }^{48}$ Lang (1976) 62 CAR 50.
} 


\section{Character and Bad Choices}

How much relies on the credibility of the victim? Does her choice to become intoxicated affect her credibility? It has been contended that 'good' victims can convince the jury without the assistance of any legal presumptions about the situation. ${ }^{49}$ However, it is questionable if a member of the public on a jury really considers a person who becomes heavily intoxicated of their own volition is a 'good' or credible victim. Past instances of intoxicated sexual encounters can be used as evidence to negate credibility if it is so coincidental to the situation at hand that it becomes relevant. ${ }^{50}$ This becomes particularly important if a victim is so intoxicated she cannot remember what occurred during her intoxicated episode. ${ }^{51}$ However, the similarities between intoxicated episodes of sexual behaviour must be astounding in order for such evidence to be adduced, otherwise this would merely perpetuate the continuing myths of 'promiscuous' women being less credible. ${ }^{52}$ Since jurors are already making common sense 'human' judgments based on their own sets of values and beliefs, such tight restrictions on character evidence can only be welcomed. ${ }^{53}$

In a study of barristers' perspectives on the use of the rebuttable presumptions of consent, such as the victim being administered a substance, it was implied that the need to use such presumptions reflected a weak case on the part of the prosecution, with little confidence in the victim's testimony being able to secure a conviction. ${ }^{54}$ It was also stated by some participants that they would be more likely to downplay the amount drank, at least by the complainant, presumably to be believed and appear more credible. ${ }^{55}$ This assertion was supported by Ryan:

Where it appears that there was a misunderstanding between the parties as to consent, the woman's moral behaviour will affect jury perceptions in deciding who was to blame for the misunderstanding. ${ }^{56}$

Jurors will question why the victim was drinking, or why she was drinking with the accused, and may interpret this as provoking the incident. ${ }^{57}$ It may be even more difficult to convince a jury if the accused is physically attractive, a paradox with this possibly also instilling in the accused a sense of entitlement. ${ }^{58}$ This may be even more prevalent in high profile cases involving celebrities. There also seems to be much made of presumptions about one behaviour automatically leading to another. A woman may invite a man to her room, intending only to engage in preliminary sexual activities, but a man takes this as an expression of consent to engage in sexual

\footnotetext{
49 Carline and Gunby (2011: 243).

50 S41 Youth Justice and Criminal Evidence Act 1999.

51 Evans [2016] EWCA Crim 452.

52 A (2001) UKHL 25 [3].

53 Gunby et al. (2010: 588-589).

54 Carline and Gunby (2011: 244).

55 Gunby et al. (2010: 590).

56 Ryan (2004: 411).

57 Kramer (1994:131).

58 Chambers Goodman (2009: 68).
} 
intercourse. Once in private, with only her word against his, these indicators may influence the jury more than they should. ${ }^{59}$

In many instances, we are trying to decide what the victim would have done in a situation because she cannot remember. The difficulty comes in the contrast between what a victim would have done sober and what they would have consented to while intoxicated. Drunk consent is still consent, and other factors, such as prior behaviour, might be a way to make that decision. It might be easy to say that the victim and accused being strangers would make it less likely that she consented, ${ }^{60}$ but if this was normal and frequent behaviour in her sex life, perhaps not. If the victim is having sex in her usual manner, does this indicate she has capacity ${ }^{61}$ Although admitting such evidence may seem to be prejudicial to the complainant, ${ }^{62}$ saying yes to one thing does not necessarily mean saying yes to all, and the accused has much to lose. A balance is needed between the interests of both parties-they have competing interests, but a fair trial must prevail. ${ }^{63}$

In the case of $H$, it was speculated that lying about involvement might be suggestive of the fact that the accused knew the victim was too drunk or not consenting. This may aid the jury in assessing the situation. ${ }^{64}$ However, if the accused openly admits to sexual relations with the victim, claiming she consented and had the capacity to do so, this is never as easy a feat. As far back as the 1960s, academics have recognised that a conviction is much less likely if the victim drinks and is not badly beaten. ${ }^{65}$ Why does this phenomenon continue in the twenty-first century? Why do we still equate drinking with bad character? Perhaps the courts and the jury still cling to the notion that the victim wants to distance themselves from bad choices made at the time, rather than appreciate that consent was not given, or the victim had no real capacity to do so. ${ }^{66}$ If the victim claims she did not consent, whether she had the capacity to do so is a moot point, because the jury are assessing who they believe, and if it is the victim, she did not consent. ${ }^{67}$

\section{Other Jurisdictions}

California's Penal Code specifies that a person's capacity to consent is presumed to be absent if they are prevented from resisting by an intoxicating substance, and the accused is aware (or should have been) of the victim's condition. ${ }^{68}$ This is evident of the need for the intoxication preventing a victim from saying no rather than requiring an affirmative yes. However, this may been seen as somewhat progressive, since

\footnotetext{
59 See Chambers Goodman (2009: 57).

60 Ciccarelli [2011] EWCA Crim 2665.

61 Stark (2017: 5).

62 Stark (2017: 5).

63 Rumney and Fenton (2011: 475), see also Lord steyn A(No 2) (2002) 1 AC 45 [46].

${ }^{64} \mathrm{H}$ [2007] EWCA Crim 2056 [30].

65 McCalden (1966: 50).

66 Finch and Munro (2006: 314).

67 Wright [2007] EWCA Crim 3473.

68 S261(a)(3) California Penal Code 2005.
} 
two-thirds of states (including New York) require a substance to be 'administered' before consent will be negated, meaning only one-third of states afford protection to victims who are voluntarily intoxicated. ${ }^{69}$ With sixteen to eighteen percent of American women and one to three percent of American men having experienced rape or attempted rape, the importance of getting the law right is paramount. ${ }^{70}$ Jury instructions in California also require the jury to consider that the victim must have had knowledge of the nature of the act or transaction involved, as well as acting freely and voluntarily (much like our freedom and capacity provisions). ${ }^{71}$

Even less protection is afforded to rape victims elsewhere in the world. Japan's rape laws are particularly archaic, and whilst recently updated (to include anal and oral, and increase sentencing from three years to five), remains focused upon sex obtained by force and intimidation. ${ }^{72}$ This definition lacks the awareness that submission and consent are not the same thing. ${ }^{73}$ It also requires a mere age of thirteen for legally recognised consent to be given. This attitude is not surprising in a society which once used Ianfu (comfort women), systematically forced into prostitution, to supress the sexual appetites of soldiers in a bid to prevent the rape of citizens of occupied areas during World War II. ${ }^{74}$ Although recent common law decisions in the last year or so have acknowledged the marital rape is possible, such decisions seem lagging behind other jurisdictions. ${ }^{75}$ In particular, a culture of victim blaming of those who come forward is prevalent, which serves as a 'function to maintain the status quo' ${ }^{76}$ This is particularly evident in the high profile case of victim Shiori Ito, a journalism student who accused an influential and well-known TV journalist of rape after asking him for an internship. Much was made of the fact that she was drinking with him before the incident, even though CCTV footage showed he had to prop her up to walk her to his hotel room, she seemed to take the blame. ${ }^{77}$ Japanese liberal MP Sugita Mio publically said Ito was to blame for drinking so much alcohol in front of her attacker and losing her memory. ${ }^{78}$

In 1992, Canada made some progressive amendments to their rape law, stating that if the accused's belief in consent was based on his intoxication, it is not a defence. ${ }^{79}$ Critics have deemed this to be too much responsibility taken away from women, but this may equally place additional responsibility on women to

\footnotetext{
69 See Ryan (2004: 413).

70 Rhode (2016: 1).

71 California Jury Instructions 10.35, see Chambers Goodman (2009: 60).

72 Article 177 Japanese Penal Code.

73 Olugboja (1982) QB 320.

74 Boling (1995: 541).

75 Shifting Attitudes Toward Sexual Violence in Japan, Masamai Ito Japan Times, 6th June 2018, www. japantimes.co.uk.

76 Shifting Attitudes Toward Sexual Violence in Japan, Masamai Ito Japan Times, 6th June 2018, www. japantimes.co.uk.

77 Shiori Ito: Japan's Attitude's to Allegations of Sexual Violence are Locked in the Past, www.bbc. co.uk.

78 Shiori Ito: Japan's Attitude's to Allegations of Sexual Violence are Locked in the Past, www.bbc. co.uk.

79 An Act to Amend the Criminal Code (Sexual Assault) ch 38 273.1-273.2 (1992).
} 
communicate their sexual desires. ${ }^{80}$ This approach seems to be in direct conflict with the usual stereotype that a drunken rapist is less culpable, whereas a drunken victim is more so. ${ }^{81}$

Lack of protection of voluntarily intoxicated rape victims perpetuates the myth that the victim was the master of their own demise; author of their own misfortune. ${ }^{82}$ This is perpetuated through many channels, such as social media and even advertisements. As Kramer has observed, adverts for beer and spirits equate a woman with a drink in her hand with a woman signalling her sexual availability. ${ }^{83}$ Such myths dilute the legislation against sexual assault, especially where alcohol is involved. ${ }^{84}$ In particular, myths seem to influence jury beliefs about appropriate behaviours based on gender. ${ }^{85}$ A lack of physical force often maintains this problematic perception from lay people, and when alcohol is added to that equation, further confusion spreads. ${ }^{86}$ As the Scottish Law Commission recognised in their report, focus should only be on behaviour that pertains to respective interactions and how this led to any agreement on consent. ${ }^{87}$ They also stress the difference between a lack of capacity to make decisions because of alcohol, and the alcohol altering the choice a person makes. ${ }^{88}$

This intricate weaving of intoxication, sexual escapades and legislation can lead to life-changing court proceedings for both parties involved. A victim from a case in New South Wales stated that she 'mourned' for the person she would have been if it was not for one particular sexual encounter. ${ }^{89}$ In this case, the judge assessed the complainant having ten standard drinks on her first night out as not being a high level of intoxication. However, the accused, who confessed to having had nine drinks at the time of the incident, was said by the judge to be moderately drunk or more. ${ }^{90}$ This unfortunate assessment confirms the double standard even prevalent in the courtroom for intoxicated accused and complainants, and may be the reason that more victims do not come forward. The more progressive a jurisdictions rape law is, the more likely victims will report crimes committed against them. In the UK, there are 530 reports of rape per million people. In Japan the number is ten. ${ }^{91}$

\footnotetext{
80 Kramer (1994: 150-151).

81 Topping (2016: 75).

82 Topping (2016: 88).

83 Kramer (1994: 115).

${ }^{84}$ Kramer (1994: 159).

85 Simpson (2016: 114).

${ }^{86}$ Chambers Goodman (2009: 66).

87 Scottish Law Commission (2007: 2.23-2.24).

88 Scottish Law Commission (2007: 2.63).

89 This Doesn't Get To Be Over For Me: The Rape Case That Put Consent on Trial, Richard Ackland, The Guardian, 20th July 2017.

90 This Doesn't Get To Be Over For Me: The Rape Case That Put Consent on Trial, Richard Ackland, The Guardian, 20th July 2017, referring to the case against Luke Andrew Lazarus who was convicted and then acquitted due to a misdirection on reasonable belief.

91 Shiori Ito: Japan's Attitude's to Allegations of Sexual Violence are Locked in the Past, www.bbc. co.uk.
} 
Usual protocol in sexual assault cases in Australia is a mandatory jury direction. The Home Office report 'Setting the Boundaries' recognised this as being an excellent form of communication with juries as to social prejudices and misconceptions. $^{92}$ In particular, in the territory of Victoria, the judge must direct the jury that the fact the victim did not indicate free agreement is enough to show the events took place without, and it should not be assumed the victim agreed because she did not protest, sustain injury, or that she had agreed on previous occasions. ${ }^{93}$ This is a positive model of consent, requiring affirmation rather than dissention, and appears to work well in a practical sense. ${ }^{94}$

Of extraordinary media fame is the decision to sentence Stanford University champion swimmer Brock Turner to only 6 months in prison after being charged with penetration of an intoxicated person, ${ }^{95}$ penetration of an unconscious person, ${ }^{96}$ and intent to commit rape. ${ }^{97}$ The prosecution had asked the court for a 6 year sentence. ${ }^{98}$ This decision was heavily criticised, especially after his release in only 3 months, and eventually led to judge Aaron Persky being removed from his post. ${ }^{99}$ This case echoed a case preceding that of turner twenty-five years earlier, where a white male Stanford student was charged only with statutory rape after plying a new student with alcohol and ignoring the victim's verbal protests. ${ }^{100}$

\section{Leading Theories}

Wallerstein's contention is that there is value in over-criminalising an area of the law. Distinguishing between factual intoxicated consent and legal intoxicated consent has much value in light of this. This makes the question of whether or not a person is capable of given consent in any given situation a legal question. ${ }^{101}$ This, in turn, leads to the query of whether or not the Bree standard is too restrictive, and requires too high a level of intoxication before capacity to consent is negated. Wallerstein's view is that drunk consent should not be viewed as valid legal consent. ${ }^{102}$ This is separated from the drunk accused and 'drunk intent' principle because, while both involve deliberate choice at the time, there are vast differences between intention and consent. This is because consent does not correlate with wanting a course of action, but merely going along one another person's. ${ }^{103}$ In direct contrast, intention

\footnotetext{
92 Home Office (2000: 2.11.2, 2.11.3).

93 S37 Crimes Act 1958 (Vic) as amended 2006.

94 Scottish Law Commission (2007: 2.33).

95 S289(e) California Penal Code.

96 S289(d) California Penal Code.

97 S220 California Penal Code.

98 Case \#B1577162 People of the State of California V Brock Allen Turner 2016.

99 Votes Oust California Judge in Brock Turner Sexual Assault Case, Sam Levin The Guardian, 6th June 2018, www.theguardian.com.

100 Case \#B9198729State v Thomas 1991.

101 Wallerstein (2009: 321).

102 Wallerstein (2009: 323).

103 Wallerstein (2009: 325).
} 
requires not only knowing your actions will bring about a result, but wanting that result and acting accordingly. ${ }^{104}$

Malm questions if consent is a state of mind, if it signifies a state of mind through one's actions, or if it evaluates if that state of mind is appropriate in the circumstances. ${ }^{105}$ Consent could be deemed a mental state of 'willingness' which could be anything from acceptance to desire. However, capacity to choose one's options in light of one's goals and values is intrinsic to this concept. Malm compares this to failure to respond at a meeting when the group are asked if there are any objections-if you do not respond, this implies consent. ${ }^{106}$ However, in the realms of sexual assault, such restraint from expressing one's wishes could be deemed fear-related submission rather than willingness.

It is completely possible that an intoxicating substance could have the effect of preventing a person from choosing an option in line with their sober values and goals. Does the 'willingness' to engage in voluntary intoxication legally negate capacity to participate in such choice? Malm also advocates that there is no real value in requiring a strictly verbal standard of consent, ${ }^{107}$ as this would require women to take active measure to protect their autonomy and have control over their own bodies, as if this is a privilege, rather than a right. ${ }^{108}$ However, allowing consent through non-verbal cues also invites higher chances of mistake, leading Australian politicians to campaign specifically for reform to rape laws asking for vocalised affirmation in order for consent to be valid. ${ }^{109}$

Kramer's recommendation is for reform which heavily reflects Canada's 1992 reforms, with additional factors added which should not be considered to indicate consent. These include dress, agreeing to be a social companion of the accused, voluntary intoxication, or any preconceptions on the part of the accused about the complainant's reputation. ${ }^{110}$

\section{The Way Forward}

There is no rational reason why myths surrounding rape and intoxication should influence legal outcomes. Wallerstein's theory for reform is that a choice made whilst sober and capable must be present in order for drunk consent to be validated. This equally supports Cole's tracing theory, which attempts to establish the 'pre-intoxicated desire' of the victim. ${ }^{111}$ This is problematic, because it presumes that we know our future intentions. ${ }^{112}$ It also ignores the fact that prior consent is

\footnotetext{
104 Duff (1998:149-150).

105 Malm (1996: 147).

106 Malm (1996: 148).

107 Malm (1996: 162).

108 Remick (1993: 1114).

109 The Times, 6th July 2018 www.thetimes.com.

110 Kramer (1994: 152).

111 Cole (2017: 164).

112 Wallerstein (2009: 335).
} 
counter-productive because it ignores our intentions at the time of the actual event. There is no reflection here of spur of the moment decisions, even if they are later regretted, though Wallerstein and Cole both concede that some women allow themselves to become intoxicated purposely with the goal of engaging in sexual relations and having the confidence to do so. ${ }^{113}$ This theory assumes women who voluntarily become intoxicated are allowing their intoxicated self to make decisions about sexual activity. ${ }^{114}$ As Finch and Munro have shrewdly observed, focus must remain on the ability of the victim to consent at the time of intercourse, and not her prior actions. $^{115}$

It appears that from studies with lay persons and 'mock jurors' that there is still an expectation of affirmation, not of the positive, but of the negative. ${ }^{116}$ That is, that a victim should actively demonstrate their lack of consent, rather than a need to actively consent in the first instance. This puts the responsibility on the victim to communicate their lack of interest in engaging in sexual activity, rather than the accused gaining a certain 'yes' from the victim. Some jurors even articulated an idea that failure to communicate non-consent is agreement to engage, much like the boardroom scenario mentioned earlier. ${ }^{117}$ However, the jurors also referred to a person who was capable. The law is still unclear as to at what point that capability is lost.

The idea that the level of intoxication needed to negate capacity to consent is too high post Bree is justified, but this must make an allowance for those who genuinely misjudge how drunk the victim is. Visual indicators, such as vomiting, stumbling and slurring should aid with assessing reasonable belief in this situation. However, the media have been less than receptive to such ideas, speculating that such amendments to the criminal law would only be 'to boost convictions'. ${ }^{118}$ Perhaps such 'symptoms' of extreme drunkenness could be added to the section 75 list of rebuttable presumptions. Proving those symptoms were in existence and the accused knew of this would prove extreme drunkenness and therefore lack of capacity due to consent, unless the defendant can rebut this with a reasonable belief in consent. Temkin and Ashworth have suggested that the list of rebuttable presumptions of consent provided by the 2003 Act does have scope for further situations to be included by common law. ${ }^{119}$ The section 75 list is said to include situation which are common sense or obvious - does this not include a person who is so intoxicated they are vomiting?

A sliding scale approach was offered by Chambers Goodman as the necessary tool to fix the problem, as long as it is flexible:

\footnotetext{
113 Wallerstein (2009: 336).

114 Cole (2017: 165).

115 Finch and Munro (2004: 798).

116 Carline and Gunby (2011: 247).

117 Finch and Munro (2006: 316).

118 Men Face Jail For Rape If Women Are Too Drunk To Consent In Bed To Boost Convictions, This is London, 28th December 2008.

119 Temkin and Ashworth (2004: 338).
} 
A sliding scale provides an opportunity for the jury to consider the level of intoxication and its relation to the appropriate or reasonable level of explicitness required for adequate consent by mandating a more unequivocal, more affirmative yes the more the female has had to drink. ${ }^{120}$

This would establish a method whereby the more the victim has had to drink, the more the requirement for a resounding 'yes' in order for legal sexual intercourse to occur, because alcohol can have quite an impact on a person's ability to resist. Without this, a significant number of women are unprotected. However, as Sir Igor Judge stated in Bree, a grid system would be very problematic. ${ }^{121}$ In the case of G, evidence of lack of capacity included blood alcohol level, eye witness evidence and psychiatric evidence, proving the victim lacked the level of cognitive functioning necessary to make reasoned decisions. ${ }^{122}$ This approach may be influential on creating such a scale.

Under the New South Wales Criminal Procedure Act (with other Australian territories such as Western Australia, Southern Australia and Tasmania having similar provisions), the judge must warn the jury that a delay in reporting does not signify the allegation is false. ${ }^{123}$ This can be difficult, as establishing a distinction between sober regrets and sober realisation is not without problems. Equally, the Home Office suggested that a direction to juries that lack of violence or resistance does not mean agreement should be given. ${ }^{124}$

\section{Conclusion}

It appears that intoxication sometimes gives inauthentic, yet legally valid consent, unless a person is almost at the point of unconsciousness. Whilst it might be morally wrong to take advantage of a person who is displaying many outward signs of being heavily intoxicated, the law still allows for this person to make decisions which may be deeply regrettable the next day. The accused may also rely on there being no sign of unwillingness rather than 'she said yes' without the need for positive affirmation in consent. ${ }^{125}$ This almost assumes that a woman who voluntarily becomes intoxicated also runs the risk of having her non-verbal cues as to unwillingness to participate in sexual activity being misread. Perhaps, as Chambers Goodman has suggested, if either party has consumed alcohol, silence should never constitute adequate legal consent. ${ }^{126}$ Silence does not signify consent in contract law or medical law, so why should it here ? $^{127}$

\footnotetext{
${ }^{120}$ Chambers Goodman (2009: 58).

121 Bree [35].

122 See Wheeler (2017: 71).

123 S294(2)(a) Criminal Procedure Act 1986.

124 Home Office (2000: 2.11.5).

125 Malm (1996: 158).

126 Chambers Goodman (2009: 60).

127 Rumney and Fenton (2008: 289).
} 
Without physical resistance as a proxy for non-consent, and a hazy memory the extremely intoxicated victim seems to be heavily lacking in protection of the law. This has been criticised as being neither practical nor just. ${ }^{128}$ In cases where alcohol is not involved, the courts have found that a victim who does not physically resist was not forced, ${ }^{129}$ so what chance does an intoxicated female have, whose credibility and behaviour is questioned? When assessing the defendant's reasonable belief in consent, if their own drunkenness is considered within 'all the circumstances', ${ }^{130}$ does this tip the scales in his favour? ${ }^{131}$ Though this might also include things favourable to the victim, such as location, ${ }^{132}$ degrading or humiliating treatment, or the victim secreting menstrual blood. ${ }^{133}$

Does acting 'freely' suggest a willingness, acting on one's desires, or simply that you are not acting 'unfreely' (under duress)? ${ }^{134}$ Perhaps the law in this area cannot be made in any more clear or transparent due to the nature of the problem itself. ${ }^{135}$ Other jurisdictions such as Japan prove that we are already fairly progressive in our classification of rape as a crime of autonomy rather than violence. Additionally, the UK has half the population yet forty times the government funding for victims of rape and sexual assault. ${ }^{136}$ However, much can be said for sending a message to citizens in the twenty-first century, where popular culture shows intoxication as the ultimate British pastime. Cases where a victim is found to have a drug like rohypnol in her system will continue to be clear cut. Outside of this, there is little certainty. We have prescribed drink limit for activities like driving, presumably because we can harm others. We should question why there is no prescribed limit for activities in private, where we might also harm others, psychologically and irreversibly.

\section{Compliance with Ethical Standards}

Conflict of interest On behalf of all authors, the corresponding author states that there is no conflict of interest.

Open Access This article is distributed under the terms of the Creative Commons Attribution 4.0 International License (http://creativecommons.org/licenses/by/4.0/), which permits unrestricted use, distribution, and reproduction in any medium, provided you give appropriate credit to the original author(s) and the source, provide a link to the Creative Commons license, and indicate if changes were made.

\footnotetext{
128 Simpson (2016: 116).

129 See Chambers Goodman (2009: 82).

130 S1(2) Sexual Offences Act 2003.

131 Temkin and Ashworth (2004: 341).

132 This Doesn't Get To Be Over For Me: The Rape Case That Put Consent on Trial, Richard Ackland, The Guardian, 20th July 2017.

133 McClaren and Whitelaw [2015] EWCA Crim 1223.

134 Austin (1961: 8).

135 Miles (2008: 8).

136 Shiori Ito: Japan's Attitude's to Allegations of Sexual Violence are Locked in the Past, www.bbc. co.uk.
} 


\section{References}

Austin, J.L. 1961. A Plea for Excuses. In Freedom and Responsibility, ed. Morris H, Stanford University Press.

Boling, D. 1995. Mass Rape, Enforced Prostitution, and the Japanese Imperial Army: Japan Eschews International Legal Responsibility. Columbia Journal of Transnational Law 32: 533.

Carline, A., and C. Gunby. 2011. How an Ordinary Jury Makes Sense of it is a Mystery: Barristers' Perspectives on Rape, Consent and the Sexual Offences Act 2003. Liverpool Law Review 32: 237-250.

Chambers Goodman, C. 2009. Protecting the Party Girl: A New Approach for Evaluating Intoxicated Consent. Brigham Young University Law Review 1: 57.

Cole, K. 2017. Sex and the Single-Malt Girl: How Voluntary Intoxication Affects Consent. Montana Law Review 78: 155.

Cowan, S. 2008. The Trouble with Drink: Intoxication, Incapacity, and the Evaporation of Consent to Sex. Akron Law Review 41: 899.

Duff, A. 1998. Intention, Mens Rea and the Law Commission Report. Criminal Law Review 147.

Elliott, C., and C. De Than. 2007. The Case for a Rational Reconstruction of Consent in Criminal Law. Modern Law Review 70: 225.

Elvin, J. 2008. Intoxication, Capacity to Consent, and the Sexual Offences Act 2003. King's Law Journal 19: 151.

Finch, E., and V.E. Munro. 2004. The Sexual Offences Act 2003: Intoxicated Consent and Drug Assisted Rape Revisited. Criminal Law Review 789-802.

Finch, E., and V.E. Munro. 2006. Breaking-Boundaries-Sexual Consent in the Jury Room. Legal Studies 26: 303-320.

Firth, G. 2011. Not an Invitation to Rape: The Sexual Offences Act 2003. Consent and the Case of the Drunken Victim Northern Ireland Legal Quarterly 62: 99.

Gunby, C., A. Carline, and C. Beynon. 2010. Alcohol-Related Rape Cases: Barristers' Perspectives on the Sexual Offences Act 2003 and its Impact on Practice. Journal of Criminal Law 74(6): 579-600.

Gunby, C., A. Carline, and C. Beynon. 2013. Regretting it After: Focus Group Perspectives on Alcohol Consumption, Non-Consensual Sex and False Allegations of Rape. Social and Legal Studies 22: 87.

Home Office, Setting the Boundaries: Reforming the Law on Sexual Offences, July 2000.

Kramer, K.M. 1994. Rule by Myth: The Social and Legal Dynamics Governing Alcohol-Related Acquaintance Rape. Stanford Law Review 47: 115.

Malm, H.M. 1996. The Ontological Status of Consent and its Implications for the Law on Rape. Legal Theory 2: 147.

McCalden, R.J. 1966. Rape. Canadian Journal of Corrections 9: 37.

Miles, J. 2008. Archbold News, 10, 6-9

Remick, L.A. 1993. Read Her Lips: Verbal Consent in Rape. University of Pennsylvania Law Review 1451: 1103-1151.

Rhode, D.L. 2016. Rape on Campus and in the Military: An Agenda for Reform. UCLA Women's Law Journal 23: 1.

Rumney, P.N.S., and R.A. Fenton. 2008. Intoxicated Consent in Rape: Bree and Jury Decision-Making. Modern Law Review 71: 279.

Rumney, P.N.S., and R.A. Fenton. 2011. Judicial Training and Rape. Journal of Criminal Law 75(6): 473-481.

Ryan, V.M. 2004. Intoxicating Encounters: Allocating Responsibility in the Law of Rape. California Western Law Review 40: 407.

Scottish Law Commission 'Report on Rape and Other Sexual Offences' No 209 SE/2007/243.

Simpson, B. 2016. Why Has the Concept of Consent Proven so Difficult to Clarify? Journal of Criminal Law 80(2): 97-123.

Stark, F. 2017. Bringing the Background to the Fore in Sexual History Evidence. Archbold Review 8: 4-8.

Temkin, J., and A. Ashworth. 2004. The Sexual Offences Act 2003: (1) Rape, Sexual Assaults, and the Problem of Consent. Criminal Law Review 328-346.

Topping, A. 2016. The Blurred Lines of Capacity to Consent in Rape. NEL Review 4: 72.

Wallerstein, S. 2009. A Drunken Consent is Still Consent-Or is it? A Critical Analysis of the Law on a Drunken Consent to Sex Following Bree. Journal of Criminal Law 73(4): 318-344.

Wheeler, J. 2017. C V G Case Comment. Journal of P I Law 2: 70-73.

Publisher's Note Springer Nature remains neutral with regard to jurisdictional claims in published maps and institutional affiliations. 